Rapid report

\title{
A comparison of methods to assess intimate partner abuse 1 year postpartum
}

\author{
Sílvia Fraga PhD ${ }^{\mathrm{a}, \mathrm{b}, *}$, Raquel Lucas PhD ${ }^{\mathrm{a}, \mathrm{b}}$, Henrique Barros PhD ${ }^{\mathrm{a}, \mathrm{b}}$ \\ a Institute of Public Health, University of Porto, Portugal \\ ${ }^{\mathrm{b}}$ Department of Clinical Epidemiology, Predictive Medicine and Public Health, University of Porto Medical School, Portugal
}

\section{A R T I C L E I N F O}

\section{Article history:}

Received 12 September 2013

Accepted 5 February 2014

Available online 15 February 2014

\section{Keywords:}

Methods

Trial

Violence

Abuse

Screening

\section{Introduction}

International prevalence estimates of intimate partner violence (IPV) during pregnancy range between $0.9 \%$ and $30 \%$ [1]. In Portugal, a prevalence of $10 \%$ of physical abuse during pregnancy was reported [2], slightly higher than the $8.5 \%$ estimate found in a population-based study of intimate partner physical violence among adult women [3].

The importance of screening for abuse during prenatal care, pregnancy, and postpartum is well recognized [4]. However, little attention has been devoted to abuse during postpartum and no estimates are available for Portugal. Leading health organizations recommend pregnant women to be routinely screened for IPV [5] although there is no agreement on the most effective disclosure method [6,7]. Given the sensitive and private nature of IPV, the choice of a particular administration method may improve participation, thereby enhancing case finding. Six trials evaluated the effectiveness of IPV assessment methods [8-13], but they evaluated specific cultural backgrounds, none provided information on European settings, and only one specifically considered pregnancy [8]. Assessment tools are difficult to harmonize across cultures, settings, and also between interviewers $[14,15]$.

\footnotetext{
* Corresponding author. Institute of Public Health of the University of Porto, Rua das Taipas 135, 4050-600 Porto, Portugal. Tel: +351-2-2206-1820; fax: +351-2-2206-1821.

E-mail address: silfraga@med.up.pt (S. Fraga).
}

We conducted a trial to identify the most effective approach to disclose IPV 1 year postpartum.

\section{Methods}

The study consisted of a follow-up of women who delivered in a Portuguese university hospital [2,16]. Written informed consent was obtained and data were confidential. This study was approved by the joint Ethics Committee of Hospital S. João and University of Porto Medical School.

\section{Trial design}

A consecutive subsample comprising 915 participants was asked permission to be contacted 1 year postpartum to follow-up on health and related lifestyles. At that moment, participants were blinded regarding the method of questionnaire administration assigned: postal $(n=305)$, face-to-face $(n=305)$, and telephone $(n=305)$. Age, education, income, smoking, prenatal visits, and abuse during pregnancy did not differ across the three randomized groups.

\section{Postal questionnaire}

Women received the questionnaire by post, with a letter explaining the study and a pre-addressed stamped envelope.

Face-to-face interview

Letters invited participant to an appointment at the Department of Obstetrics of Hospital de São João, loosely scheduled so that 
women could come at their best convenience. The questionnaire was administered by the interviewer.

\section{Telephone interview}

Women who did not participate through the initial method assigned were given the opportunity to choose any of the other two methods.

Women were contacted by telephone and asked to answer a paper questionnaire filled out by the interviewer, scheduled according to their convenience.

Questionnaires included demographic and behavioral characteristics and health services utilization, and the validated Abuse Assessment Screen was used to assess physical abuse [17]. Women were asked whether they had been hit, slapped, kicked, or otherwise physically abused during the postpartum period.

Interviewers received training and positive cases remained confidential. Referral to psychosocial support was offered as recommended [18]. $\chi^{2}$ test was used to compare estimates between the three groups.

\section{Results}

Participants allocated to answer by postal questionnaire presented an initial response rate of $50.5 \%$, significantly lower than that obtained by face-to-face (91.5\%) and telephone $(92.8 \%, P<.001)$ (Fig. 1). Considering the initial allocation method and ignoring further contact efforts, the frequency of abuse was lower among the group of women inquired by post $(5.8 \%)$ compared with telephone (7.4\%) or face-to-face interview $(10.8 \%, P=.159)$.

After allowing subsequent recovery of data with a different method, we found similar estimates of abuse for the three initially allocated groups. Prevalence was $8.1 \%$ among those allocated to the postal questionnaire, whereas $10.3 \%$ reported IPV in the group assigned to face-to-face and $7.6 \%$ in the group allocated to telephone $(P=.479)$. However, after categorizing women according to the actual response method (independently of initial allocation), prevalence of physical abuse was 5.4\% among those whose information was obtained by post and $11.7 \%$ and $7.6 \%$ among those who answered by face-to-face and telephone questionnaires, respectively $(P=.040)$.

\section{Discussion}

The prevalence of IPV may be affected by differences in the true frequency of abuse in the target population but also by methodological options, which influence participation rate and the willingness to disclose abuse. In our study, face-to-face and telephone interviews resulted in higher participation rates than postal questionnaires. Overall, face-to-face interview was the best approach to

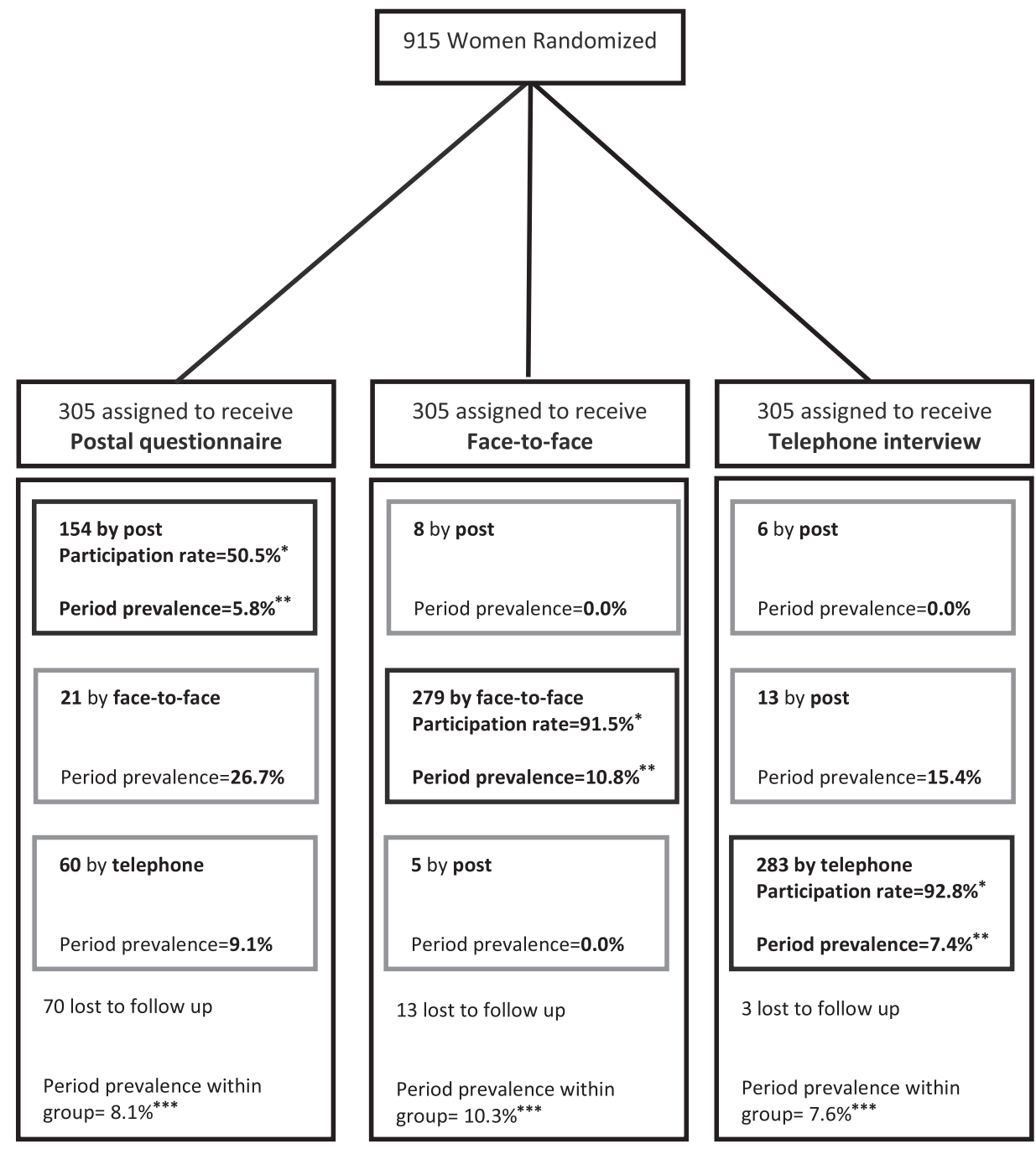

Fig. 1. Flow of participants through the trial. $\chi^{2}$ test for comparison between estimates: ${ }^{*} P<.001 ;{ }^{* *} P=.159 ;{ }^{* * *} P=.479$. 
obtain abuse disclosure in this setting. Although participants were not initially asked about the preferred mode of inquiry, women who did not answer using the initially allocated response mode but ultimately decided to participate, most often opted for telephone or face-to-face interviews, and clearly declined to respond by post.

Other studies that assessed women's preference showed that faceto-face interviews were the least favored [9] and the selfadministered method was significantly preferred compared with disclosing IPV directly to a health-care provider [19,20]. Most women rescheduled initially belonged to the post group. Therefore, when contacted by other method, they were probably aware about the study objective. These women could prefer to disclose IPV to someone who could directly listen to their experiences instead of disclosing in writing. Many cultural reasons, as well as national standards for training of health professionals, may explain the observed difference across countries. In Portugal, for instance, there is not much of a tradition in completing postal questionnaires, which may explain the lower response rate. Also, the lower disclosure of abuse by post could be attributed to fear of revictimization or simply because they felt less comfortable disclosing a negative experience in such a distant way.

Despite the observed prevalence differences by method, the three initially allocated groups showed similar abuse estimates regardless of the actual mode of inquiry. Face-to-face interviews were more likely result in the report of abuse supporting the importance of the method of inquiry.

These findings are as part of the first Portuguese research about violence during pregnancy [16] addressing frequency and effects on birth outcomes [2]. It raised awareness about abuse during pregnancy, leading to policy decisions regarding prenatal screening and prevention of violence. The present study aimed to provide additional evidence on the most effective approach to screen abuse, suggesting that it should be part of the face-to-face contact of pregnancy-related visits.

\section{Acknowledgments}

We gratefully acknowledge grants from Fundação para a Ciência e a Tecnologia (FCOMP-01-0124-FEDER-021439) and (SFRH/BD/44408/ 2008). The authors thank Lúcia Rocha for organizing the fieldwork and the staff of the Department of Obstetrics, Hospital S. João, Porto.

\section{References}

[1] Taillieu TL, Brownridge DA. Violence against pregnant women: prevalence, patterns, risk factors, theories, and directions for future research. Aggression Violent Behav 2010;15(2010):14-35.
[2] Rodrigues T, Rocha L, Barros H. Physical abuse during pregnancy and preterm delivery. Am J Obstet Gynecol 2008;198(2):171. e1-6.

[3] Costa D, Soares JJ, Lindert J, Hatzidimitriadou E, Sundin O, Toth O, et al. Prevalência de violência entre parceiros íntimos na Europa. Gac Sanit 2013;27(Supl C2):15.

[4] Daoud N, Urquia ML, O’Campo P, Heaman M, Janssen PA, Smylie J, et al. Prevalence of abuse and violence before, during, and after pregnancy in a national sample of Canadian women. Am J Public Health 2012;102(10):1893-901.

[5] ACOG technical bulletin. Domestic violence. Number 209-August 1995 (replaces no. 124, January 1989). American College of Obstetricians and Gynecologists. Int J Gynaecol Obstet 1995;51(2):161-70.

[6] Feder G, Ramsay J, Dunne D, Rose M, Arsene C, Norman R, et al. How far does screening women for domestic (partner) violence in different health-care settings meet criteria for a screening programme? Systematic reviews of nine UK National Screening Committee criteria. Health Technol Assess 2009:13(16):iii-iv, xi-xiii, 1-113, 37-347.

[7] Nelson HD, Bougatsos C, Blazina I. Screening women for intimate partner violence: a systematic review to update the U.S. Preventive Services Task Force recommendation. Ann Intern Med 2012;156(11):796-808. W-279, W80, W-81, W-82.

[8] Kataoka Y, Yaju Y, Eto H, Horiuchi S. Self-administered questionnaire versus interview as a screening method for intimate partner violence in the prenatal setting in Japan: a randomised controlled trial. BMC Pregnancy Childbirth 2010;10:84.

[9] MacMillan HL, Wathen CN, Jamieson E, Boyle M, McNutt LA, Worster A, et al. Approaches to screening for intimate partner violence in health care settings: a randomized trial. JAMA 2006;296(5):530-6.

[10] Ahmad F, Hogg-Johnson S, Stewart DE, Skinner HA, Glazier RH, Levinson W Computer-assisted screening for intimate partner violence and control: a randomized trial. Ann Intern Med 2009:151(2):93-102.

[11] Rhodes KV, Drum M, Anliker E, Frankel RM, Howes DS, Levinson W. Lowering the threshold for discussions of domestic violence: a randomized controlled trial of computer screening. Arch Intern Med 2006; 166(10):1107-14.

[12] Chen PH, Rovi S, Washington J, Jacobs A, Vega M, Pan KY, et al. Randomized comparison of 3 methods to screen for domestic violence in family practice. Ann Fam Med 2007:5(5):430-5.

[13] Bair-Merritt MH, Feudtner C, Mollen CJ, Winters S, Blackstone M, Fein JA. Screening for intimate partner violence using an audiotape questionnaire: a randomized clinical trial in a pediatric emergency department. Arch Pediatr Adolesc Med 2006;160(3):311-6.

[14] Ruiz-Perez I, Plazaola-Castano J, Vives-Cases C. Methodological issues in the study of violence against women. I Epidemiol Community Health 2007;61(Suppl 2):ii26-31.

[15] Fraga S, Costa D, Dias S, Barros H. Does interview setting influence disclosure of violence? A study in elderly. Age Ageing 2012;41(1):70-5.

[16] Rocha L. [Physical violence against pregnant women: effects on women's health and newborn]. Porto: University of Porto Medical School; 2006.

[17] McFarlane J, Parker B, Soeken K, Bullock L. Assessing for abuse during pregnancy. Severity and frequency of injuries and associated entry into prenata care. JAMA 1992;267(23):3176-8.

[18] Putting women first: ethical and safety recommendations for research on domestic violence against women. Geneva: World Health Organization 2001.

[19] Glass N, Dearwater S, Campbell J. Intimate partner violence screening and intervention: data from eleven Pennsylvania and California community hospital emergency departments. J Emerg Nurs 2001;27(2):141-9.

[20] Webster J, Holt V. Screening for partner violence: direct questioning or selfreport? Obstet Gynecol 2004;103(2):299-303. 